\title{
Experimental Investigation of Performance of Parabolic Solar Cooker in NEH Region of India
}

\author{
Mahendra Singh Seveda ${ }^{1}$, Sudhir Narayan Kharpude ${ }^{2 *}$ and Narale Pradip Digambar ${ }^{2}$ \\ ${ }^{1}$ Department of Renewable Energy Engineering, College of Agricultural Engineering and \\ Post-Harvest Technology, Central Agricultural University, Ranipool, Gangtok, Sikkim, India \\ *Corresponding author
}

\section{A B S T R A C T}

\section{Keywords}

Solar cooker,

Parabolic dish cooker, Solar insolation, Efficiency, Sikkim

\section{Article Info}

Accepted:

30 May 2020

Available Online:

10 June 2020
Solar energy has prime importance in supply of food and energy to human survival and sustenance. Cooking is the most common way of utilization of solar energy. The scientific community has developed different models of solar cookers and tested their performance in variable climatic conditions of different parts of the world. In this experimentation, parabolic solar cooker with dish concentrator system with a point focus collector having manual sun tracking has been evaluated for its performance in NEH region of India. The procedure for experimentation followed measurement of solar insolation, temperature changes in cooker and ambience atmosphere, relative humidity and wind velocity. The parameters were measured at an interval of 30 minutes from 6:00 AM to 6:00 PM each day. The results suggested that highest pot temperature attained without load was $94.5^{\circ} \mathrm{C}$ and with load was $97.08^{\circ} \mathrm{C}$. The efficiency of solar cooker was found to be $37 \%$ for experimental site of Sikkim.

\section{Introduction}

Energy, now a days is a need as like food, clothing and shelter. Energy is vital element for the development of economic, social and industrial growth. Energy acts as an indicator to suggest development of country. Energy to earth comes from major prime source 'Sun'. Solar energy is harnessed from sun while all other forms of energy are indirect solar energy. This energy can be converted into electrical, mechanical, thermal, chemical and various other forms of energy (Glaser, 1968; Crabtree and Lewis, 2007; Energy, 2013; Karakoti, Das and Bandyopadhyay, 2013). Solar technologies are broadly characterized as either passive solar or active solar depending on the way they capture, convert and distribute solar energy (Panwar et al., 2012). Active solar techniques include the use 
of photovoltaic panels and solar thermal collectors to harness the energy. Passive solar techniques include orienting a building to the Sun, selecting materials with favourable thermal mass or light dispersing properties, and designing spaces that naturally circulate air.

The Sun is the most prominent feature in our solar system. The sun's great energy release is the result of an elaborated chemical process in the sun's core. This energy is radiated from the sun in all directions and a very small fraction of its reaches the earth through space in the form of energy called photons. Solar energy is the radiation produced by nuclear fusion reactions in the core of the sun. The half portion of solar radiation from sun reaches earth's atmosphere, out of which 30\% of solar radiation gets reflected back and around 15-20\% gets diffused. Unfortunately, the atmospheres and clouds absorb large amount of sunlight. So, the amount of light that reaches any point on the ground depends on the time of day, the day of the year, the amount of cloud cover and the latitude at that point, with the solar focus directly dependent on three of these factors. (Rai, 1997; Duffie and Beckman, 2013; Karakoti, Das and Bandyopadhyay, 2013)Global solar radiation in India is around $4-7 \mathrm{kWh} / \mathrm{m}^{2} /$ day with an average of 250-300 sunny days in a year. Rajasthan and Gujarat receive maximum global solar radiation in the range of6 to 7 $\mathrm{kWh} / \mathrm{m}^{2} /$ day. Sikkim receives about 5 to 5.2 $\mathrm{kWh} / \mathrm{m}^{2} /$ day. The average global radiation in India is 4 to $5 \mathrm{kWh} / \mathrm{m}^{2} /$ day. Peak solar radiation is about $1000 \mathrm{Watt} / \mathrm{m}^{2}$ (Tyagi, 2009; Ramachandra, Jain and Krishandas, 2011).

\section{Solar cooker}

As we look through the scenarios and practices implemented for cooking food, we find that cooking fuels are fossilized commercial fuels or non-commercial firewood, cow-dung cakes and forest residues. Their impacts on climate change and deforestation are issues of concern. Being direct and indirect solar energy, these fuels are produced due to process of photosynthesis, animal waste generation and other degradations. Use of solar energy directly for cooking can help in reducing fuel burden and deforestation. (Tucker, 1999) Also, it is observed that common peoples cannot afford commercial fuels as well as they are not reachable to them in remote areas. Solar cookers can be seen as an alternative to their cooking needs. Although a variety of solar cookers have been developed, but these are not in use as expected due to its incompatibility with traditional cooking practices which are in minds of housewives. It is a simple, safe and convenient way to cook food without consuming fuels, heating up the kitchen and polluting the environment. It is appropriate for of millions of people around the world with scare fuel and financial resource to pay for cooking fuel. Solar cookers can also be used for boiling of drinking water, providing access to safe drinking water to millions of people thus preventing waterborne illnesses. Solar cookers have many advantages, on the health, time and income of the users and on the environment (Ahmad, 2001; Pohekar, Kumar and Ramachandran, 2005; Pohekar and Ramachandran, 2006; Wentzel and Pouris, 2007; Toonen, 2009).

There are generally three types of solar cookers box-type, concentrating type and panel type cookers. They vary in size, weight, cost, durability, portability and cooking time. (Ahmad, 2001; Yettou et al., 2014) Solar panel and solar box cookers are enclosed type of cookers. They use transparent cover to trap the solar energy and a black pot to capture, absorb and concentrate infrared light into generation of heat and its overall segregation in pot. Panel cookers have a flat panel which 
reflects and focuses sunlight for cooking and heating. In case of concentrating type cookers, concentrators or reflectors or mirrors concentrate i.e. point solar radiation into a single beam of radiation having high focusing temperature on to a pot with black bottom. Parabolic solar cookers quickly generate intense heat for frying and boiling. The parabolic concentrating solar cooker is the only class of solar cooker that is truly suitable for frying, as the temperature at the focus is marginally equals the temperature range obtained from conventional electric, gas, or wood fired stoves (Rai, 1997; Panwar, Kaushik and Kothari, 2012; Kumar, Shukla and Kumar, 2018). The concentrator type of cookers generally is of three sub-types Spherical, Parabolic and Fresnel lens type. For this study a parabolic concentrator type solar cooker was used as the parabolic shape of concentrator with aid of reflecting material can concentrate solar energy into a focal point. High temperature range of 200 and $300^{\circ} \mathrm{C}$ can be achieved with the help of combination of the circular design, the size and the polished aluminium. It is suitable for baking, roasting and grilling(Herez, Ramadan and Khaled, 2018; Aramesh et al., 2019).

The impact of types of reflectors used in parabolic dish cooker was studied by Reddy et al.(2015)and they concluded that maximum efficiency is achievable by using mirror type reflectors. The mirror type reflectors have 10 $15 \%$ more efficiency than the aluminium sheet reflectors. The aluminium sheet reflectors cooker is easy to fabricate and its durability and handling is more convenient and comfortable than mirror type reflectors. The achieved maximum temperature during experimentation was $123^{\circ} \mathrm{C}$. Motwani and Patel (2019)in their study have stated that maximum meals can be prepared in the temperature range of $60-100^{\circ} \mathrm{C}$. The brief review of solar parabolic trough collectors has been provided by Upadhyay, Patel and
Ramana (2019) and they revealed parabolic trough collector technology has vast uses and its efficiency can be enhanced by using phase change materials (PCM). According to Akayleh, Al-soud and Al-jufout (2018) the use of mechanical tracking can be a innovative approach in solar parabolic trough collectors for concentrating solar radiations cooking purposes and bread baking which require higher temperature ranges. The energetic and exergetic study carried out by Cuce \& Cuce (2015) for various geometric designs of solar cooker has revealed that dish type parabolic cookers showed highest performance as well as maximum heat loss coefficient. The low cost solar parabolic cooker by Eswaramoorthy \& Shanmugam (2012) has attained a reasonable collection efficiency with highest attained temperature of $450^{\circ} \mathrm{C}$ at average solar radiation range of $950 \mathrm{~W} / \mathrm{m}^{2}$. The overall thermal efficiency of cooker was $60 \%$ while the daily operation efficiency was found as $40 \%$.

While reviewing above cited references it was revealed that there is a need to utilize solar cooker for cooking. Sustainable energy solutions are necessary in developing nations as current food preparation practices are becoming harmful to the environment, economic development and the overall health of the population. Considering, lacuna in research related solar cooker for areas of $\mathrm{NEH}$ region of Sikkim current study has been taken for research. The purpose of this study was to analyze the system and predict its behavior when subjected to the solar conditions of Sikkim, India.

\section{Materials and Methods}

This section deals with the material and methodology adopted for experimental analysis on thermal performance of parabolic solar cooker. This study was conducted at the roof top of the North block building, College 
of Agricultural Engineering and Post-Harvest Technology, Central Agricultural University, Ranipool, Gangtok, Sikkim.

\section{Experimental setup}

The tests were carried out in the Solar Yard, Department of Renewable Energy Engineering, College of Agricultural Engineering and Post-Harvest Technology, Central Agricultural University, Ranipool, Gangtok, Sikkim, which is located at $27.2914^{\circ} \mathrm{N}$ latitude and $88.5916^{\circ} \mathrm{E}$ longitude. The schematic of parabolic solar cooker is as shown in Fig. 1 and 2 illustrates the photographic view of system.

The parabolic solar dish concentrator system is a point focus collector that tracks the sun manually by constant monitoring of human operator based on pin shadow located on the aperture of the collector. The dish surface was covered by galvanized sheet metal laminated by highly reflective aluminum. The highly reflective aluminum foil laminated galvanized sheet metal was carefully assembled with dish frame to get the focal point precisely. The system consists of parabolic dish, cooking pot, pot holder, and dish holder. Dimensions of parabolic dish reflector are shown in figure 3. The parabolic dish collector is oriented in south direction to receive maximum solar radiation. The detail technical specifications of parabolic solar cooker system are given in Table 1.

\section{Performance evaluation of parabolic solar cooker}

The tests were conducted from $06.00 \mathrm{~h}$ to $18.00 \mathrm{~h}$ during month of November-2019. While recording observations a 30 minute interval was considered. The parameters recorded during analysis were Ambient Temperature $\left({ }^{\circ} \mathrm{C}\right)$, Temperature of Parabolic $\operatorname{Dish}\left({ }^{\circ} \mathrm{C}\right)$, Pot Temperature Without load $\left({ }^{\circ} \mathrm{C}\right)$,
Pot Temperature With load $\left({ }^{\circ} \mathrm{C}\right)$, Solar Insolation $\left(\mathrm{W} / \mathrm{m}^{2}\right)$, Wind Velocity $(\mathrm{m} / \mathrm{sec})$ and Relative Humidity (\%). Based on these values further calculation to determine efficiency of cooker were carried out.

\section{Thermal efficiency of parabolic solar cooker}

The standard testing procedures are available to test performance of solar cookeras per Mullick, Kandpal and Saxena (1987) and Mullick, Kandpal and Kumar (1996) along with ASAE S580.1 a code for testing and reporting solar cooker performance. The performance of a solar cooker depends on various climatic parameters like solar radiation, ambient temperature, wind speedetc. In general solar cooker performance determination consists of evaluation of cooking time, amount of time required to boil water and highest temperature at load and Noload conditions.

The thermal efficiency of solar cooker can be calculated as per following equation 1 while equation 2 provides the cooking power of cooker.

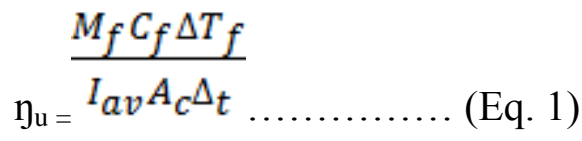

Where,

$\mathrm{\eta}_{\mathrm{u}}=$ Overallthermal efficiency $(\%)$

$M_{f}=$ mass of cooking fluid $(\mathrm{kg})$

$C_{f}=$ specific heat of cooking fluid $\left(\mathrm{J} / \mathrm{kg}^{\mathrm{o}} \mathrm{K}\right)$

${ }^{\Delta} T_{f}=$ difference between the maximum and ambient air temperature.

$I_{a v}=$ average solar intensity $\left(\mathrm{W} / \mathrm{m}^{2}\right)$ during the time interval.

$A_{c}=$ is the aperture area $\left(\mathrm{m}^{2}\right)$ of the cooker.

$\Delta_{t}=$ time required to achieve the maximum temperature of the cooking fluid (s). 


\section{Cooking power estimation}

Funk (2000) discussed two types of test variables for cooking power estimation. From Funk's definition, cooking power, $P$, is defined as the rate of useful energy available during heating period. It may be determined as a product of the change in water temperature for each interval, mass and specific heat capacity of the water contained in the cooking utensil. Dividing the product by the time (600 seconds contained in a ten minute intervals according to American Society of Agricultural Engineers) contained in a periodic interval yields the cooking power in watt:

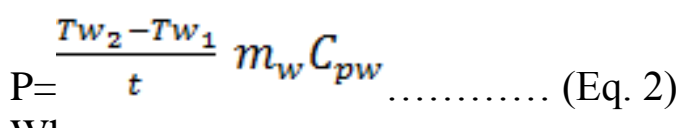

Where;

$\mathrm{P}=$ cooking power $(\mathrm{w})$.

$T w_{2}=$ final water temperature $\left({ }^{\circ} \mathrm{C}\right)$.

$T w_{1}=$ initial water temperature $\left({ }^{\circ} \mathrm{C}\right)$.

$\mathrm{t}=$ time $(\mathrm{s})$.

$m_{w}=$ mass of water $(\mathrm{kg})$.

$C_{p w}=$ water heat capacity $(4.168 \mathrm{~kJ} / \mathrm{kg} \mathrm{K})$.

\section{Standardized Cooking Power $\left(P_{s}\right)$}

Funk (2000) also introduced the term standard or adjusted cooking power which can be expressed as:

$\mathrm{P}_{\mathrm{g}}=\frac{700 \mathrm{MC}_{\mathrm{W}} \Delta \mathrm{T}_{\mathrm{w}}}{600 \mathrm{G}_{\mathrm{s}}}------(\mathrm{Eq} \cdot 3)$

Where, $\mathrm{P}_{\mathrm{s}}=$ Standard cooking power, $\mathrm{W}$, $\Delta \mathrm{T}_{\mathrm{w}}=$ Temperature difference of water load in every 10-minute intervals, ${ }^{\circ} \mathrm{C}$, and $\mathrm{G}_{\mathrm{s}}=$ Average solar radiation on surface during this time period, $\mathrm{W} \cdot \mathrm{m}^{-2}$.

As per this test protocol wind speed should be less than $1 \mathrm{~m} / \mathrm{s}$ and water temperatures of the pots should be recorded in between 40 and $90^{\circ} \mathrm{C}$. Ambient temperature and solar radiation should be in the range of $20-35^{\circ} \mathrm{C}$ and $450-1100 \mathrm{~W} / \mathrm{m}^{2}$, respectively (Funk, 2000).

\section{Results and Discussion}

This section deals with the results obtained in various tests conducted for evaluation of thermal performance of parabolic solar cooker. The parabolic solar cooker was tested in the month of November, 2019 at interval of 30 minute between 6:00 to 18:00 h each day. The experimental data such as Pot temperature without load, solar collector (parabolic dish) temperature, solar insolation, and ambient temperature, Pot temperature with load and wind velocity were recorded. The recorded data were analyzed to evaluate the performance of the system.

This experiment was carried out in the month of November 2019. The readings were taken at every 30 minutes interval from morning 06:00 hours to evening 18:00 hours. The Pot temperature with and without load were measured by a thermometer and infrared thermometer respectively, the reading was measured in ${ }^{\circ} \mathrm{C}$. The anemometer gives the reading in $\mathrm{m} / \mathrm{s}$ and solar radiation meter in $\mathrm{W} / \mathrm{m}^{2}$ while relative humidity was measured in $\%$. During experimentation no load test and full load test was carried.

During no load test the empty pot was used and tests were carried out for 4 days. The $\mathrm{T}_{\mathrm{A}}$ and $\mathrm{T}_{\mathrm{D}}$ are ambient and dish temperatures respectively. The dish temperature $\mathrm{T}_{\mathrm{D} 1}, \mathrm{~T}_{\mathrm{D} 2}$, $\mathrm{T}_{\mathrm{D} 3}$ and $\mathrm{T}_{\mathrm{D} 4}$ was measured for four spots 1,2 , 3 and 4 respectively. The figure 4 depicts graphical representation of daily temperature variation during no load test. Figure 5 depicts variation of average pot temperature, average surface temperature of dish and solar radiation with time during no load test. During no load test it was observed that as 
solar radiation intensity was increasing, the pot temperature was also increasing. It was also observed that the highest intensity of solar radiation during 4 days was $990 \mathrm{~W} / \mathrm{m}^{2}$. Despite the lower ambient temperature the cooker was providing maximum pot temperature of $94.5^{\circ} \mathrm{C}$ (Fig. 6).

During load test the pot was filled with water and test were carried out. The measurement of experimental parameters shown that the highest water temperature of $100.1^{\circ} \mathrm{C}$ at peak solar radiation observed of $960 \mathrm{~W} / \mathrm{m}^{2}$. The highest water temperature of $31.5^{\circ} \mathrm{C}$ and $56.5^{\circ} \mathrm{C}$ was observed at peak radiation intensity of $242 \mathrm{~W} / \mathrm{m}^{2}$ and $510 \mathrm{~W} / \mathrm{m}^{2}$ respectively. The results of experiment of load test with water are presented in Figure 7. During load test it was observed that due to lesser ambient temperature the water tends to cool quite earlier and more rapidly but at a lesser rate observed than the pot during no load test. In case of box type solar cooker it might have not cooled that rapidly due to use of insulation across the box in which cooking pots are kept. The efficiency of solar cooker was found $37 \%$ at highest during the experimentation and was found lowest for cloudy days.

Table.1 Specifications of the parabolic solar cooker

\begin{tabular}{|l|l|}
\hline \begin{tabular}{|l|} 
1. Collector \\
a. Collector area
\end{tabular} & $0.20 \mathrm{~m}^{2}$ \\
\hline b. Collector type & Parabolic dish \\
\hline c. Dish height & $0.31 \mathrm{~m}$ \\
\hline d. Dish width & $0.98 \mathrm{~m}$ \\
\hline e. Dish material & Anodized aluminium sheet \\
\hline 2. Cooking pot & \\
\hline a. Type & Box \\
\hline b. Inner pot material & Aluminium \\
\hline c. Outer pot material & Aluminium/Black pained \\
\hline d. Pot diameter & $0.16 \mathrm{~m}$ \\
\hline e. Pot height & $0.058 \mathrm{~m}$ \\
\hline f. Volume & $1.165 \times 10^{-3} \mathrm{~m}^{3}$ \\
\hline 3. Dish holder & \\
\hline a. Material & Aluminium \\
\hline b. Length & $111 \mathrm{~cm}$ \\
\hline c. Height & $56 \mathrm{~cm}$ \\
\hline d. Thickness & $1.5 \mathrm{~mm}$ \\
\hline 4. Pot holder & \\
\hline a. Material & Aluminium \\
\hline b. Length & $98 \mathrm{~cm}$ \\
\hline c. Thickness & $1.5 \mathrm{~mm}$ \\
\hline
\end{tabular}


Figure.1 Schematic view of parabolic solar cooker

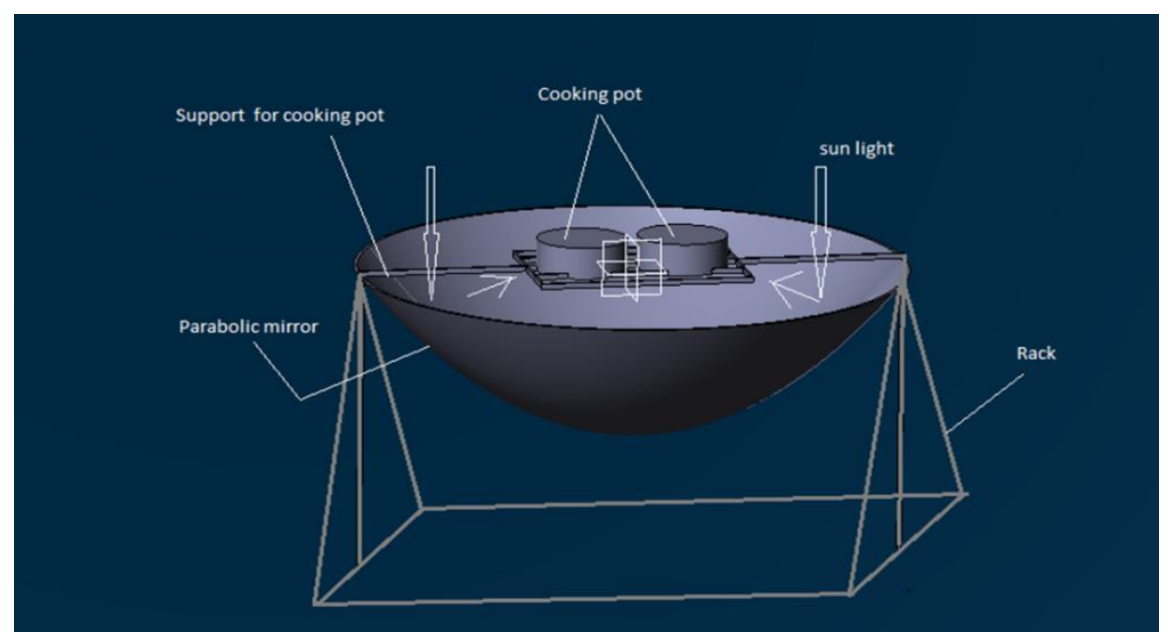

Figure.2 Photographic view of parabolic solar cooker

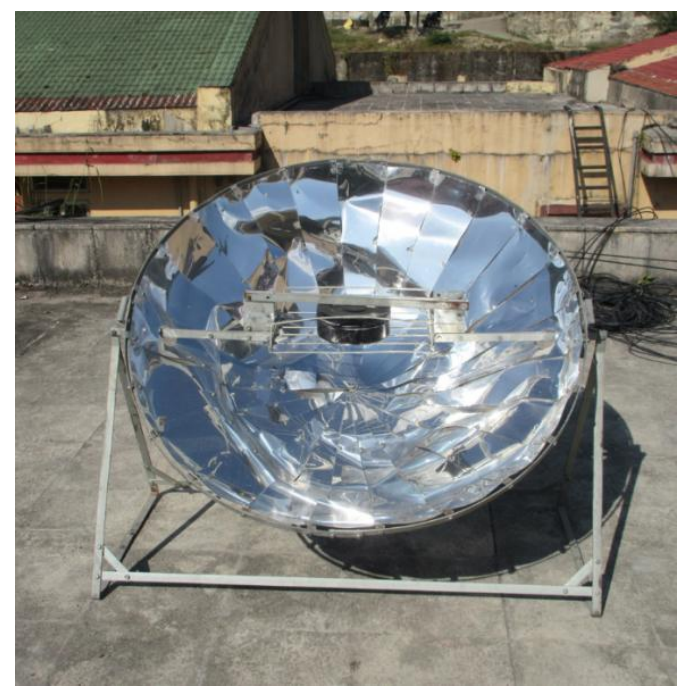

Figure.3 Dimensions of parabolic dish used for testing

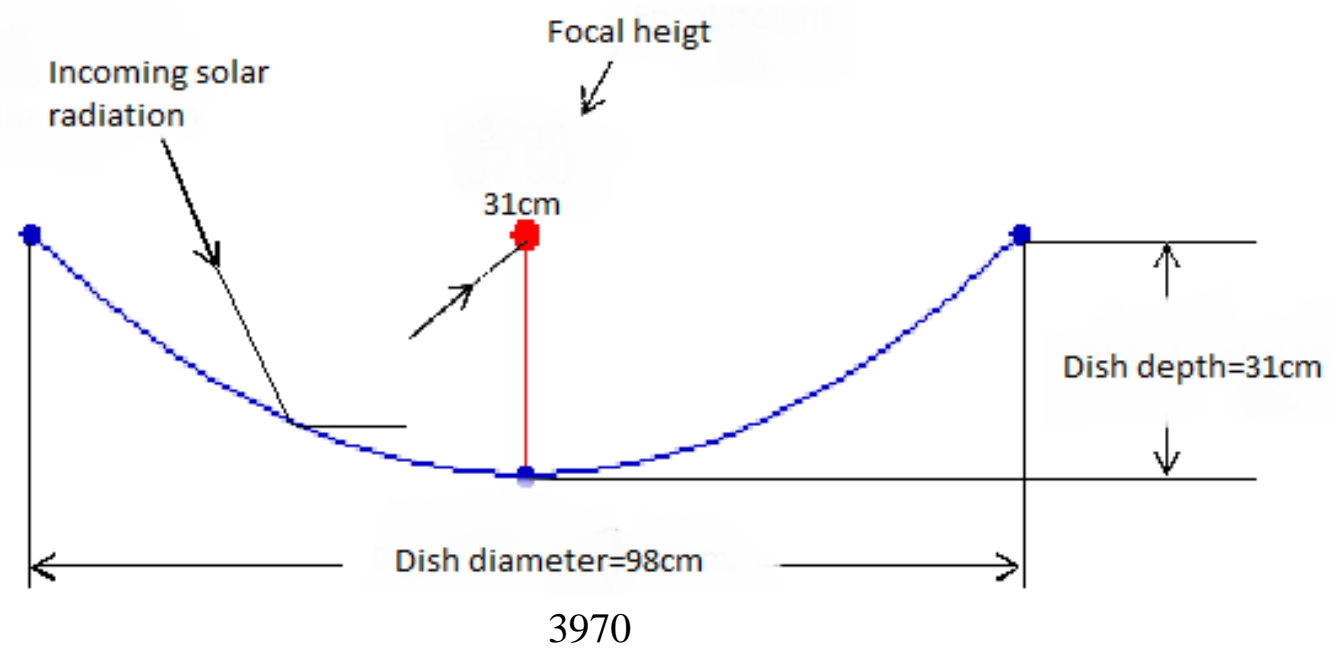


Figure.4 Variation of average water temperature with time

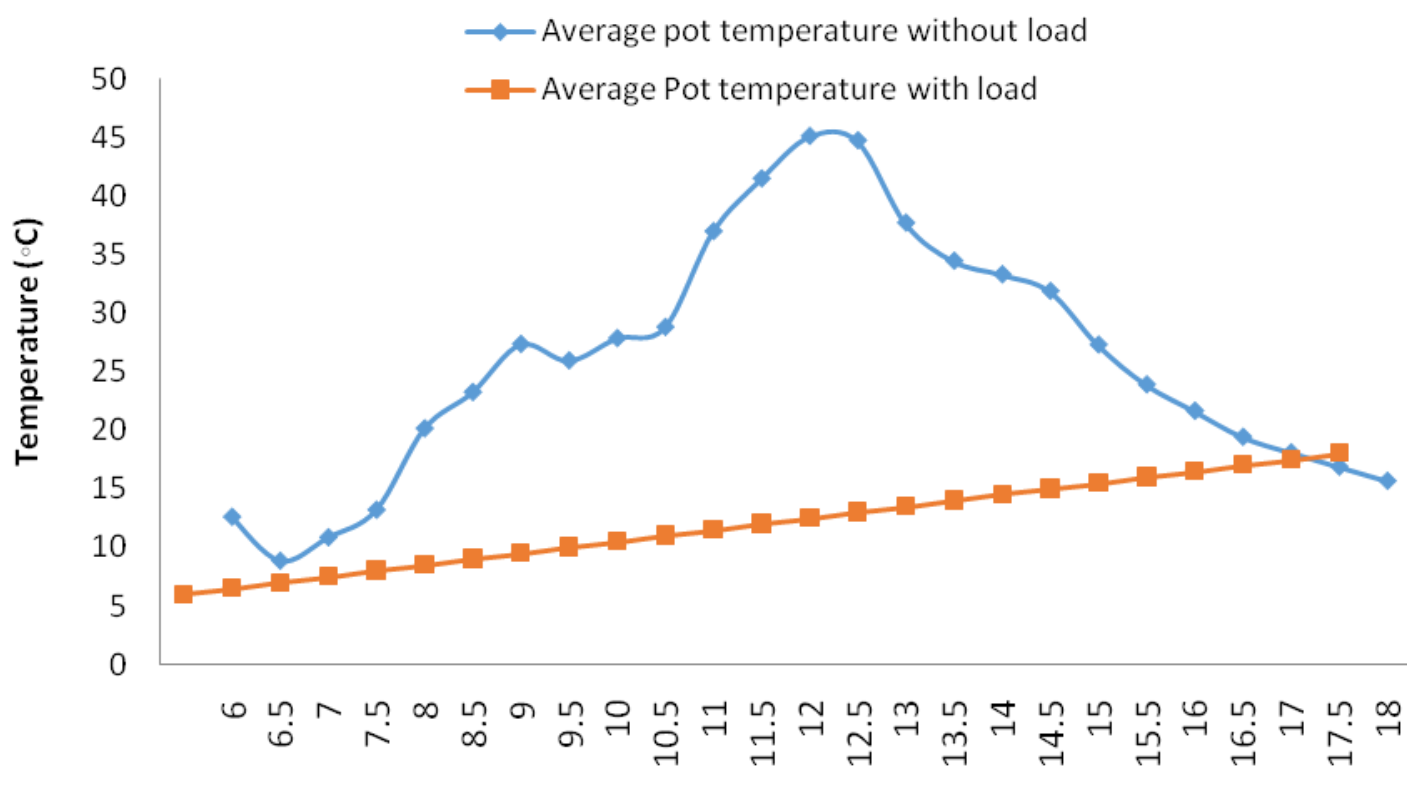

Time (h)

Figure.5 Variation of average pot temperature, average surface temperature of dish and solar radiation with time during no load test

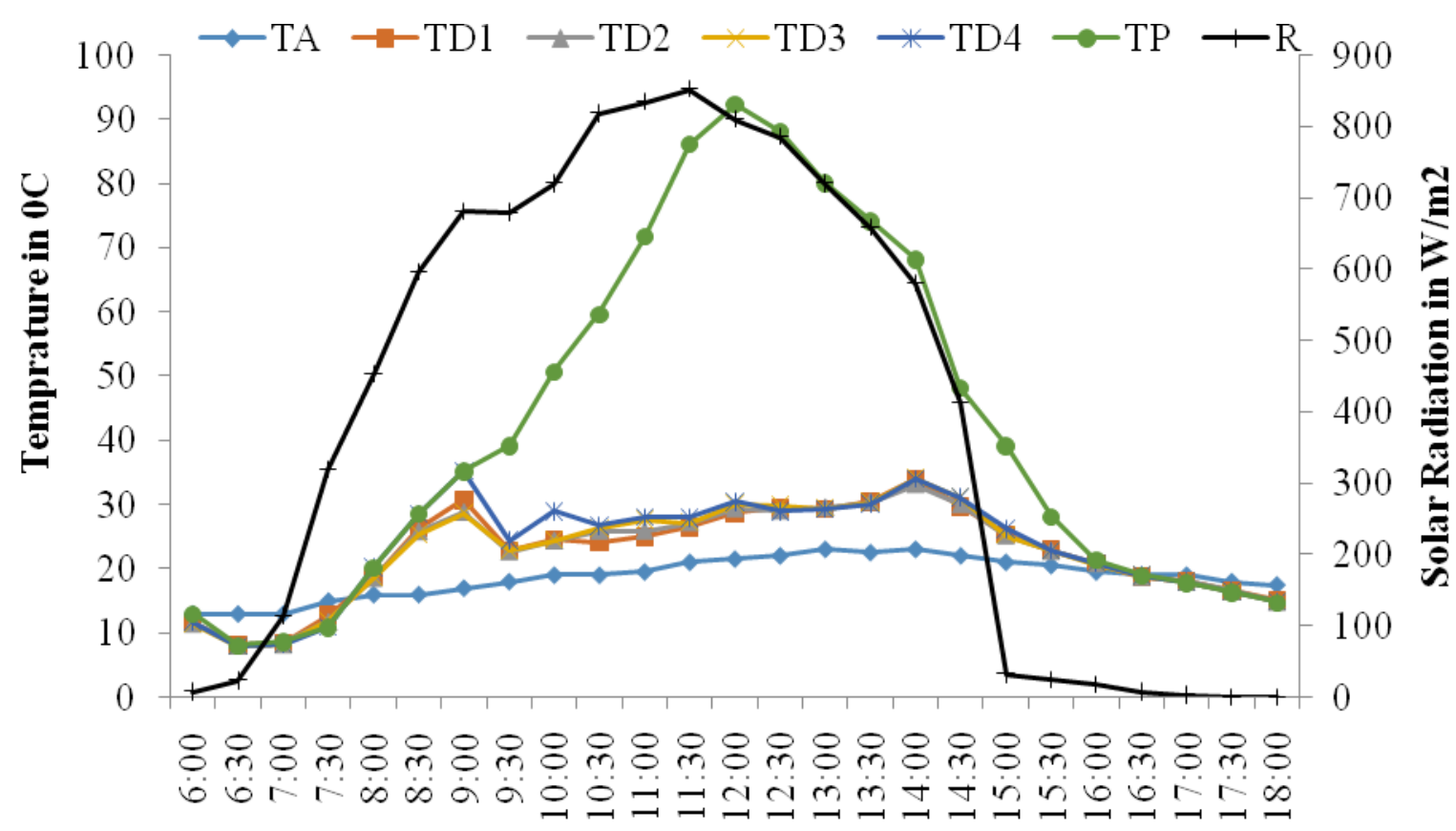

Time 
Figure.6 Variation of average ambient temperature and average surface temperature of collector with time

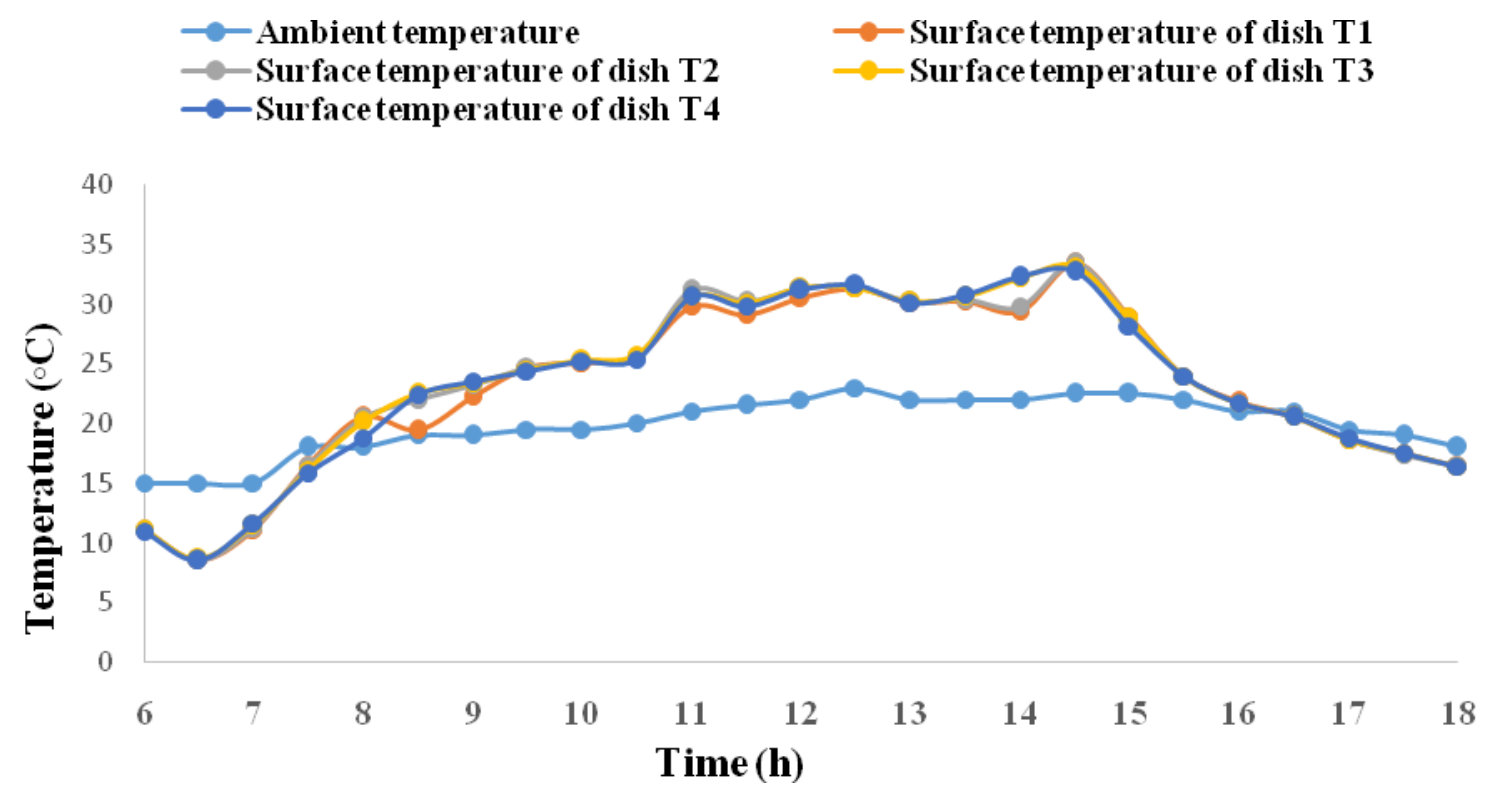

Figure.7 Variation of average pot temperature, average surface temperature of dish and solar radiation with time during full load test

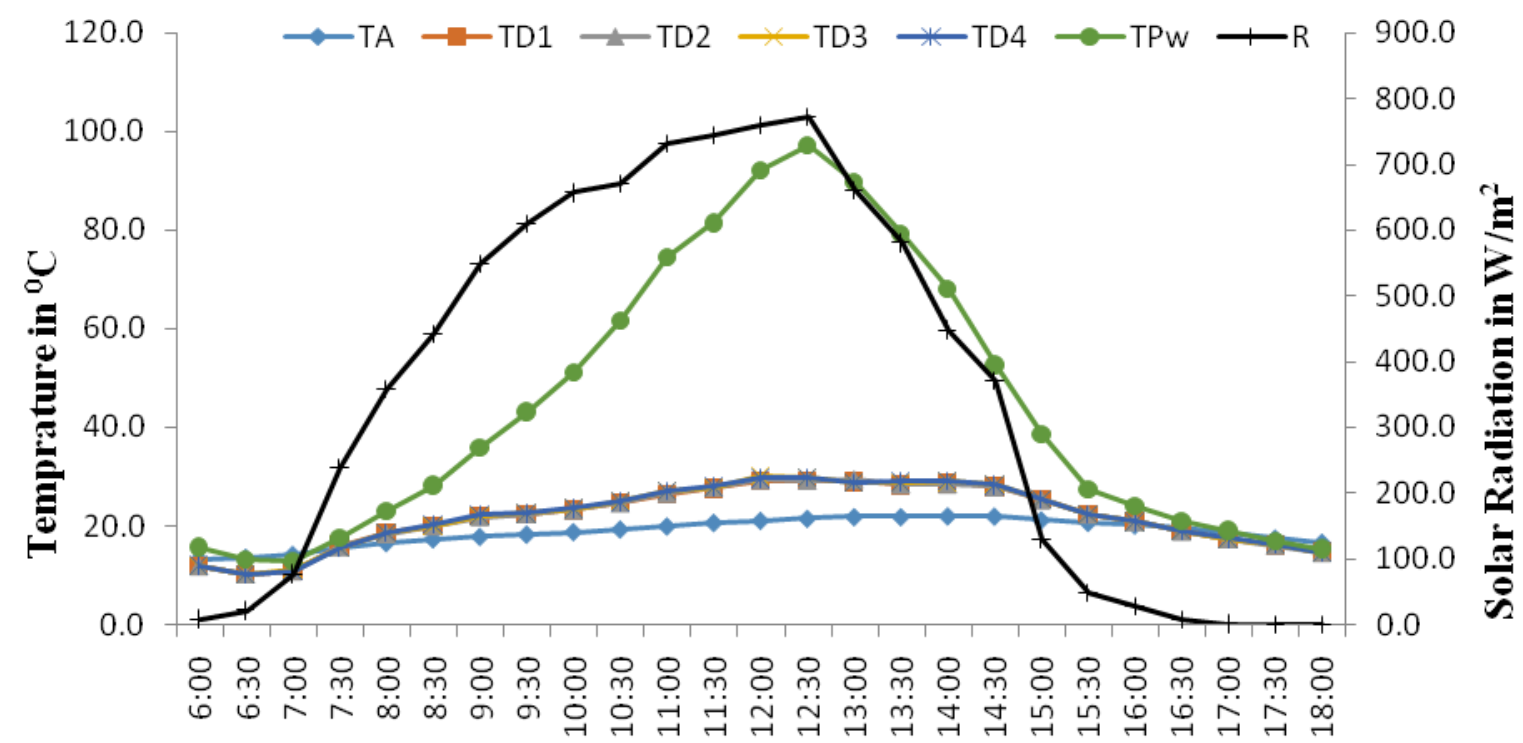

\section{Time}

The typical temperature peak period for cooking was observed from 08:30 hrs. to 13:30 hrs. During all load test except cloudy days water kept inside the pot was attending the temperature near to boiling point on each instance. The maximum ambient temperature 
and the surface temperature of the collector was $23^{\circ} \mathrm{C}$ and $30^{\circ} \mathrm{C}$ at $12: 30 \mathrm{hrs}$ and $13: 30 \mathrm{hrs}$ respectively. The maximum average ambient temperature and average surface temperature of the collector was $22.9^{\circ} \mathrm{C}$ and $30.3^{\circ} \mathrm{C}$ at 14:00 hrs and 13:00 hrs respectively. The maximum pot temperature with and without load was $92^{\circ} \mathrm{C}$ and $91^{\circ} \mathrm{C}$ at $12: 30 \mathrm{hrs}$ and $12.00 \mathrm{hrs}$ respectively. The maximum average pot temperature with and without load was $98^{\circ} \mathrm{C}$ and $97^{\circ} \mathrm{C}$ at $12: 00 \mathrm{hrs}$ and $12.30 \mathrm{hrs}$ respectively. The maximum relative humidity was $84 \%$ in the morning at 06:00 hrs. The average relative humidity was $97 \%$ attained at 07:00 hrs. During experimentation the data of relative humidity and wind velocity was also measured. Their variations suggest that chilly and humid climate is observed during experimentation time for early morning and early evening timing of experimentation. This has resulted into fall of temperature and which also reduces efficiency as larger time energy is required to start up the process of cooking. This suggests that cooking of various products is possible.

In conclusion, a thermal performance of parabolic solar cooker was experimentally investigated in NEH region of India. In the present investigations the study has been made to find the effect of intensity of solar radiations, ambient temperature and wind velocity on the water temperature with time. It was concluded from the results that highest pot temperature attained without load was $94.5^{\circ} \mathrm{C}$ and with load was $97.08^{\circ} \mathrm{C}$. It was found from the experiment that the tested parabolic solar cooker is having thermal efficiency of $37 \%$ in the month of November 2019. The experimental results showed that standardized cooking power $\left(\mathrm{P}_{\mathrm{s}}\right)$ obtained was $47.50 \mathrm{~W}$. The solar parabolic cooker was satisfactorily used to heat the water. The use of this solar parabolic cooker promotes utilization of solar energy which helps to protect environment and reduce health.

\section{References}

Ahmad, B. (2001) 'Users and disusers of box solar cookers in urban India', Solar Energy, 69, pp. 209-215. doi: 10.1016/s0038092x(01)00037-8.

Akayleh, A. S., Al-soud, M. S. and Al-jufout, S. A. (2018) 'Design and Development of a Solar-Based Cooker with a Mechanical Sun Tracking System', International Journal of Ambient Energy. Taylor \& Francis, 0(0), pp. 1-8. doi: 10.1080/01430750.2018.1472644.

Aramesh, M. et al., (2019) 'A Review of Recent Advances in Solar Cooking Technology', Renewable Energy. Elsevier B.V. doi: 10.1016/j.renene.2019.03.021.

Crabtree, G. W. and Lewis, N. S. (2007) 'The Sun provides Earth with a staggering amount of', (March), pp. 37-42. doi: 10.1111/j.13653040.2009.02017.x.

Cuce, E. and Cuce, P. M. (2015) 'Energetic and exergetic performance assessment of solar cookers with different geometrical designs', International Journal of Ambient Energy, 36(2), pp. 62-69. doi: 10.1080/01430750.2013.823111.

Duffie, J. A. and Beckman, W. A. (2013) Solar engineering of thermal processes. John Wiley \& Sons.

Energy, U. S. D. of (2013) 'The Histroy of Solar Technology', Pennyhill Press.

Eswaramoorthy, M. and Shanmugam, S. (2012) 'The Thermal Performance of a Low Cost Solar Parabolic Dish Collector for Process Heat The Thermal Performance of a Low Cost Solar Parabolic Dish Collector for Process Heat', Energy Sources, Part A: Recovery, Utilization, and Environmental Effects, 34(18), pp. 1731-1736. doi: 10.1080/15567036.2010.490825.

Funk P A. 2000. Evaluating the International Standard Procedure for testing solar cookers and reporting performance. Solar Energy, 68(1), 1-7.

Glaser, P. E. (1968) 'Power from the sun: Its future', Science. American Association for the Advancement of Science, 162(3856), pp. 857-861.

Herez, A., Ramadan, M. and Khaled, M. (2018) 'Review on solar cooker systems: Economic and environmental study for different 
Lebanese scenarios', Renewable and Sustainable Energy Reviews, 81(August 2017), pp. 421-432. doi: 10.1016/j.rser.2017.08.021.

Karakoti, I., Das, P. K. and Bandyopadhyay, B. (2013) 'An analytical study on daily solar radiation data', Current Science, 105(2), pp. 215-224.

Kumar, A., Shukla, S. K. and Kumar, A. (2018) 'Heat loss analysis: An approach toward the revival of parabolic dish type solar cooker', International Journal of Green Energy. Taylor \& Francis, 00(00), pp. 1-10. doi: 10.1080/15435075.2018.1423978.

Motwani, K. and Patel, J. (2019) 'Cost Analysis of Solar Parabolic Trough Collector for Cooking in Indian Hostel - A Case Study', International Journal of Ambient Energy. Taylor \& Francis, 0(0), pp. 1-17. doi: 10.1080/01430750.2019.1653968.

Mullick, S. C., Kandpal, T. C. and Kumar, S. (1996) 'Testing of box-type solar cooker: Second figure of merit F2 and its variation with load and number of pots', Solar Energy, 57(5), pp. 409-413. doi: 10.1016/S0038092X(96)00116-8.

Mullick, S. C., Kandpal, T. C. and Saxena, A. K. (1987) 'Thermal test procedure for box-type solar cookers', Solar Energy, 39(4), pp. 353360. doi: 10.1016/S0038-092X(87)80021-X.

Panwar, N. L., Kaushik, S. C. and Kothari, S. (2012) 'State of the art of solar cooking: An overview', Renewable and Sustainable Energy Reviews. Elsevier Ltd, 16(6), pp. 3776-3785. doi: 10.1016/j.rser.2012.03.026.

Pohekar, S. D., Kumar, D. and Ramachandran, M. (2005) 'Dissemination of cooking energy alternatives in India - a review', 9, pp. 379393. doi: 10.1016/j.rser.2004.05.001.

Pohekar, S. D. and Ramachandran, M. (2006) 'Utility assessment of parabolic solar cooker as a domestic cooking device in India', Renewable Energy, 31(11), pp. 1827-1838. doi: 10.1016/j.renene.2005.09.014.

Rai, G. D. (1997) 'Solar energy utilization, Khanna Pub', New Delhi.

Ramachandra, T. V, Jain, R. and Krishnadas, G. (2011) 'Hotspots of solar potential in India', Renewable and Sustainable Energy Reviews. Elsevier Ltd, 15(6), pp. 3178-3186. doi: 10.1016/j.rser.2011.04.007.

Reddy, R. M. et al., (2015) 'Experimental Investigation of Performance of Parabolic Solar Cooker with Different Reflectors', Journal of Energy, Heat and Mass Transfer, 37, pp. 147-160.

Toonen, H. M. (2009) 'Adapting to an innovation: Solar cooking in the urban households of Ouagadougou (Burkina Faso)', Physics and Chemistry of the Earth. Elsevier Ltd, 34(1-2), pp. 65-71. doi: 10.1016/j.pce.2008.03.006.

Tucker, M. (1999) 'Can solar cooking save the forests ?', 31, pp. 77-89.

Tyagi, A. P. (2009) 'Solar Radiant Solar Radiant Energy', Renewable Energy, p. 4179.

Upadhyay, B. H., Patel, A. J. and Ramana, P. V (2019) 'A detailed review on solar parabolic trough collector', International Journal of Ambient Energy. Taylor \& Francis, 0(0), pp. 1-21. doi: 10.1080/01430750.2019.1636869.

Yettou, F. et al., (2014) 'Solar cooker realizations in actual use: An overview', Renewable and Sustainable Energy Reviews. Elsevier, 37(0), pp. 288-306. doi: http://dx.doi.org/10.1016/j.rser.2014.05.018.

Wentzel, M. and Pouris, A. (2007) 'The development impact of solar cookers: A review of solar cooking impact research in South Africa', 35, pp. 1909-1919. doi: 10.1016/j.enpol.2006.06.002.

\section{How to cite this article:}

Mahendra Singh Seveda, Sudhir Narayan Kharpude and Narale Pradip Digambar. 2020. Experimental Investigation of Performance of Parabolic Solar Cooker in NEH Region of India. Int.J.Curr.Microbiol.App.Sci. 9(06): 3964-3974. doi: https://doi.org/10.20546/ijcmas.2020.906.465 